\title{
FIREWALL E SEGURANÇA DE SISTEMAS APLICADO AO LINUX
}

\author{
Rodrigo Ribeiro' \\ Juliana Facchini de Souza ${ }^{2}$ \\ Marcio Jose Sembay ${ }^{3}$ \\ Cassandro Albino Devenz ${ }^{4}$ \\ Ingrid Solange Sepúlveda Muñoz ${ }^{5}$
}

Resumo: Tendo em vista a evolução da internet no mundo, torna-se necessário investir na segurança da informação, alguns importantes conceitos referentes as redes de computadores e sua evolução direcionam para o surgimento de novas vulnerabilidades. O objetivo principal deste trabalho é comprovar que, por meio da utilização de software livre como o Linux e suas ferramentas, é possível criar um cenário seguro contra alguns ataques, por meio de testes em ambientes controlados utilizando-se de arquiteturas testadas em tempo real e verificando qual o potencial de uso entre uma pesquisa autoral sobre o assunto, a partir dessa ideia, foi possível reconhecer a grande utilização dos mecanismos de segurança, validando a eficiência de tais ferramentas estudadas na mitigação de ataques a redes de computares. Os sistemas de defesa da plataforma Linux são extremamente eficientes e atende ao objetivo de prevenir uma rede de acesso indevido.

Palavras-chave: Redes; Segurança; Métodos de defesa.

\footnotetext{
${ }^{1}$ Ciência da Computação, Centro Universitário Unifacvest, Brasil. E-mail: guigo_ribeiro@hotmail.com.

${ }^{2}$ Ciência da Computação, Centro Universitário Unifacvest, Brasil. E-mail: jufacchini1@gmail.com.

${ }^{3}$ Ciência da Computação, Centro Universitário Unifacvest, Brasil. E-mail: m_sembay@yahoo.com.br.

${ }^{4}$ Ciência da Computação, Centro Universitário Unifacvest, Brasil. E-mail: cassandro_al@hotmail.com.

${ }^{5}$ Ciência da Computação, Centro Universitário Unifacvest, Brasil. E-mail: ismunoz3@gmail.com.
} 